\title{
LA FAMILIA BURSERACEAE EN EL ESTADO DE AGUASCALIENTES, MÉXICO
}

\author{
Margarita Elia de la Cerda-Lemus
}

\begin{abstract}
Universidad Autónoma de Aguascalientes, Centro de Ciencias Básicas, Departamento de Biología, Avenida Universidad 940, Ciudad Universitaria, 20100 Aguascalientes, Aguascalientes, México.
\end{abstract}

\section{RESUMEN}

Se presenta el estudio de los árboles y arbustos de la familia Burseraceae que se localizan en el estado de Aguascalientes, México. Se incluye una clave para la identificación de las especies, descripciones con datos de nombre común, altitud, abundancia, localidad en la cual fueron encontradas, mapas de distribución e ilustraciones. Se reconoce la presencia de seis especies de Bursera: B. bipinnata, B. fagaroides, B. multijuga, B. palmeri, B. penicillata y $B$. roseana, la mayoría localizadas en el municipio de Calvillo, en selva baja caducifolia y matorral subtropical a 1650-2500 m. B. fagaroides es la de más amplia distribución y abundancia en el estado.

Palabras clave: Aguascalientes, Bursera, Burseraceae, México.

\begin{abstract}
An account of the species of trees and shrubs of the family Burseraceae in the state of Aguascalientes, Mexico is presented. It includes a key for the identification of species, descriptions, data concerning common names, elevation, abundance and local distribution, as well as distribution maps and illustrations. Six species of Bursera were found: $B$. bipinnata, B. fagaroides, B. multijuga, B. palmeri, B. penicillata and B. roseana. Most of them are located in the municipality of Calvillo in dry tropical forest and subtropical scrub at altitudes between $1650-2500 \mathrm{~m}$. Bursera fagaroides is the most widely distributed and abundant species in the state.
\end{abstract}

Key words: Aguascalientes, Bursera, Burseraceae, México. 


\section{INTRODUCCIÓN}

La presente contribución forma parte del proyecto "Flora del estado de Aguascalientes" iniciado en el Departamento de Biología de la Universidad Autónoma de Aguascalientes en 1980, del que han derivado numerosas revisiones de familias de angiospermas y gimnospermas. Se integran las seis especies de Bursera localizadas hasta el momento en la entidad. Es necesario comentar que se considera que el género no está aún suficientemente estudiado a pesar de las numerosas revisiones ya publicadas, entre ellas las de Stanley (1923) y Standley y Steyermark (1946). La mayor diversidad de Bursera en México se encuentra en la cuenca del río Balsas. Aguascalientes, por su ubicación geográfica, tiene pocos representantes de este grupo (Rzedowski et al., 2005).

Área de estudio

El estado de Aguascalientes se localiza en la región del Altiplano Mexicano. Se ubica entre los $21^{\circ} 38^{\prime} 03^{\prime \prime}$ y $22^{\circ} 27^{\prime} 06^{\prime \prime}$ de latitud norte y los $101^{\circ} 53^{\prime} 09^{\prime \prime}$ y los $103^{\circ} 00^{\prime} 51^{\prime \prime}$ de longitud oeste (Fig. 1).

En general el clima de Aguascalientes es del tipo semiseco BS (García, 1964) con varios subtipos. El $\mathrm{BS}_{1} \mathrm{kw}(\mathrm{w})$, semiseco templado, se presenta en $80 \%$ de la superficie del estado. El BS, hw, semiseco semicálido, lo hace en parte de los municipios del sur, suroeste, centro y norte de la entidad. Hacia el noreste en el municipio de Asientos, se encuentra una pequeña franja con clima un poco más seco del tipo seco semicálido $\mathrm{BS}_{0} \mathrm{hw}(\mathrm{w})$. En el municipio de Calvillo se encuentran zonas con clima del tipo (A)Cw semicálido subhúmedo.

El estado tiene una topografía relativamente accidentada, con algunas elevaciones al norte y noroeste, correspondientes a las prolongaciones de la Sierra Fría de Zacatecas. El intervalo altitudinal oscila desde 1600 hasta $3000 \mathrm{~m}$.

En más de la mitad del territorio estatal prevalece el tipo de vegetación característico de las regiones áridas y semiáridas, denominado matorral xerófilo (Rzedowski, 1978), en el cual según el Instituto Nacional de Estadística y Geografía (Anónimo, 1981), se reconocen el matorral espinoso y el inerme. El primero se localiza principalmente en zonas más planas y accesibles, por lo que muestra gran disturbio causado por el hombre y el ganado; en este ambiente se localizó de manera constante a Bursera fagaroides, formando con frecuencia parte de las cercas vivas que dilimitan los terrenos. 
de la Cerda-Lemus: La familia Burseraceae en el estado de Aguascalientes, México

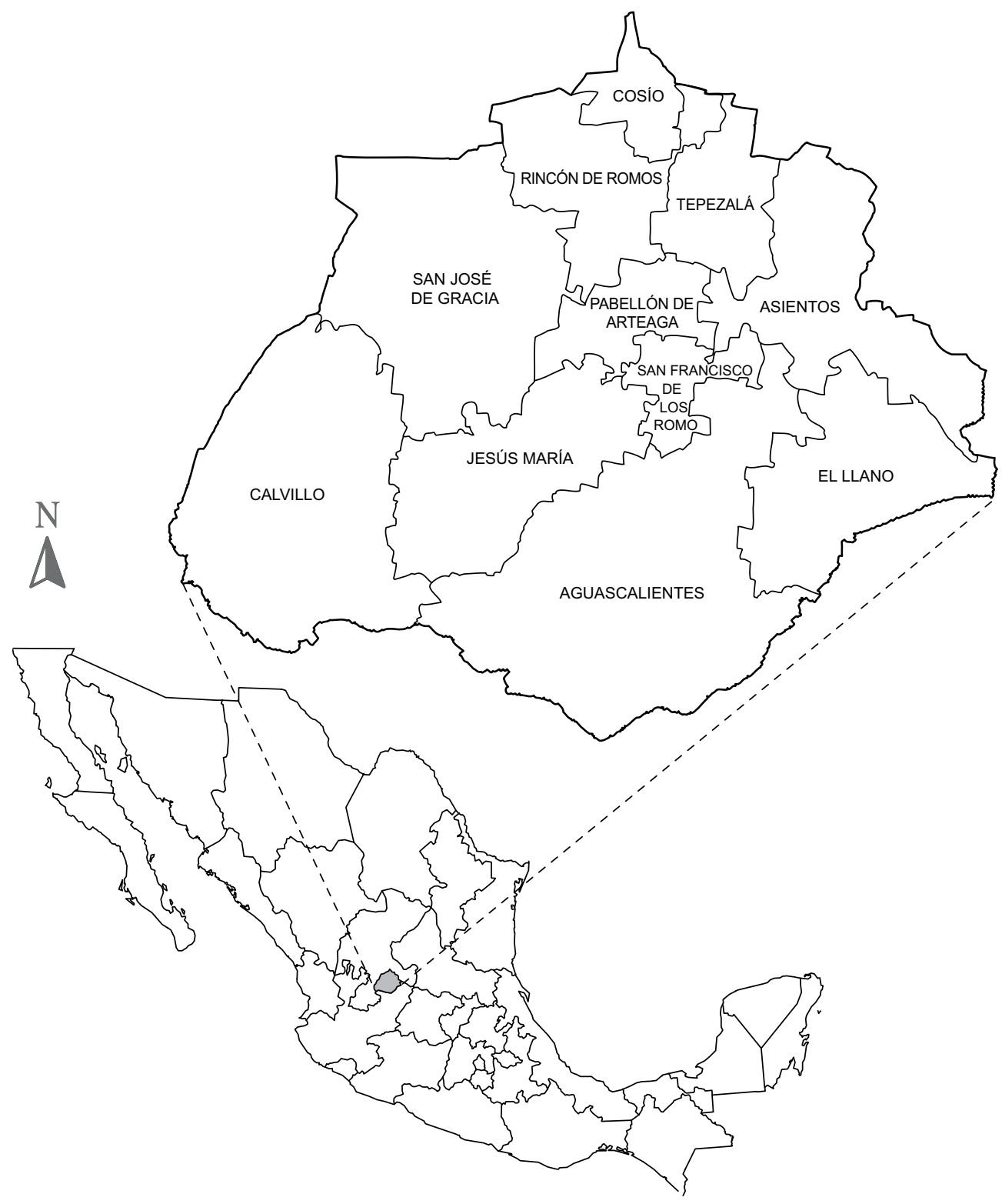

Fig. 1. Localización geográfica del estado de Aguascalientes. Fuente: Cedillo y Mares (1994). 
En el municipio de Calvillo se localizan manchones de selva baja caducifolia, una de las comunidades vegetales que está siendo severamente afectada por las actividades humanas. También existen allí colindando con San José de Gracia y Jesús María, pequeñas áreas de vegetación similar, pero con mayor disturbio, considerada como matorral subtropical. Allí predominan plantas propias de clima cálido, tales como leguminosas arbóreas, cactáceas columnares y la mayoría de las especies de Bursera tratadas en el presente trabajo: B. bipinnata, B. fagaroides, B. palmeri y B. penicillata.

\section{MATERIALES Y MÉTODOS}

En la realización de esta contribución se hizo una búsqueda bibliográfica, así como la revisión del material botánico de las especies del género Bursera colectados en el estado de Aguascalientes y depositados en los herbarios CIIDIR, ENCB, IEB, INEGI y MEXU. Se llevaron a cabo recorridos de campo en los 11 municipios de la entidad para la recolección de ejemplares, y se obtuvo información de los nombres comunes registrados en la zona, altitud, abundancia y tipos de vegetación en donde se localizan. Para la determinación de especies, claves taxonómicas y descripciones, se consideraron los trabajos de Bullock, 1936, McVaugh y Rzedowski, 1965, Rzedowski y Guevara-Féfer, 1992, Rzedowski y Calderón de Rzedowski, 1996, y Rzedowski et al., 2004, 2005 y 2007. Se elaboraron mapas de distribución geográfica de las especies e ilustraciones de las mismas. Los ejemplares colectados se encuentran depositados en el herbario de la Universidad Autónoma de Aguascalientes (HUAA). Se enviaron duplicados a CIIDIR, IEB, INEGI, MEXU y QMEX.

\section{FAMILIA BURSERACEAE KUNTH}

Árboles o arbustos (dioicos o polígamo-dioicos) provistos de resina y a menudo de aceite esencial; hojas alternas, por lo general imparipinnadas, algunas veces bipinnadas, trifolioladas o reducidas a un solo folíolo, los folíolos laterales opuestos, generalmente sin estípulas; inflorescencias axilares o terminales, básicamente cimosas pero también se presentan paniculadas, pseudoracimosas o fasciculadas, rara vez flores solitarias; flores casi siempre unisexuales, pequeñas, actinomorfas, trímeras, tetrámeras o pentámeras, rara vez hexámeras; cáliz más o menos cupuliforme, dividido en 3 a 5(6) segmentos connados o casi libres, valvados, contortos o abiertos en botón; pétalos 3 a 5(6), rara vez ausentes, libres o en pocos casos unidos para 
formar un tubo, contortos o valvados en botón; estambres dispuestos en 1 o 2 verticilos, del mismo número que las divisiones del cáliz o con más frecuencia dos veces más numerosos, por lo general estériles en las flores femeninas (que a menudo dan la apariencia de ser hermafroditas), filamentos por lo común libres, insertos debajo o rara vez sobre el disco, anteras biloculares, con dehiscencia longitudinal, disco anular o cupuliforme, a veces inconspicuo; pistilo 1, el ovario súpero, 2 a 5-locular y de otros tantos carpelos, placentación axilar, óvulos 2 por cada lóculo, estilo corto o casi obsoleto, estigma 2 a 5-lobado; fruto drupáceo con pericarpio generalmente carnoso, pero a menudo finalmente dehiscente por medio de 2 a 5 valvas, huesos (endocarpios lignificados) 1 a 5 , casi siempre monospermos y con frecuencia cubiertos por un pseudoarilo; semillas sin endospermo, embrión por lo común recto a curvo (Rzedowski y Guevara-Féfer, 1992).

Familia de unos 20 géneros y más de 600 especies, distribuidas en las regiones tropicales del mundo, con mayor diversidad en América, el norte y sur de África y en Malasia. Desde el punto de vista económico algunas burseráceas son importantes por las resinas (copal) y los aceites esenciales que producen, utilizadas en ceremonias religiosas, en cosmetología y en la medicina popular. En la flora del estado de Aguascalientes está representada únicamente por el género Bursera.

BURSERA Jacq. ex L., Sp. P1. 2: 471. 1762, nom. conserv. Terebinthus P. Browne, Hist. Jam. 345. 1756, non Terebinthus Miller, 1754. Elaphrium Jacq., Enum. P1. Carib. 3. 1760.

Árboles o a veces arbustos caducifolios, dioicos o polígamo-dioicos, rara vez hermafroditas, por lo general fuertemente resinosos y aromáticos; corteza externa de las partes lignificadas provista de una capa de clorénquima, la del tronco a menudo rojiza o amarillenta y exfoliante, otras veces gris, lisa y sin exfoliarse; ramillas abreviadas (braquiblastos) comúnmente presentes; hojas sin estípulas, a menudo dispuestas en forma de roseta en el extremo del braquiblasto, otras veces alternas y esparcidas sobre ramas jóvenes y vigorosas, en la mayoría de las especies imparipinnadas y con los folíolos opuestos, pero a veces bipinnadas, trifolioladas o simples (unifolioladas), el raquis en muchas especies alado, a las hojas normales en muchos casos les anteceden en aparición una o varias rosetas de catáfilos más o menos precozmente caedizos, de forma oblonga o triangular, y es también muy frecuente que las primeras hojas en aparecer sean trifolioladas o con un número de folíolos más reducido que el común de la especie; inflorescencias axilares, originándose por lo general con o antes de las primeras hojas, que a menudo se observan como si fueran 
fasciculadas o aglomeradas sobre los braquiblastos, en forma de panículas, tirsos, (pseudo-) racimos, cimas, glomérulos o bien por reducción las flores solitarias, bractéolas por lo general presentes; flores casi siempre unisexuales, rara vez hermafroditas, pequeñas, 3 a 5(6)-meras; cáliz profundamente dividido, sus lóbulos abiertos en botón; corola de prefloración valvada, a menudo conduplicado-valvada, los pétalos por lo general más largos que el cáliz, blanquecinos, amarillentos, verdosos o rojizos, con frecuencia cuculados; estambres dos veces más numerosos que los pétalos, dispuestos en dos series iguales o en ocasiones desiguales, los filamentos insertos en la base del disco, anteras dorsifijas, más pequeñas y estériles en las flores femeninas, disco glandular, anular; ovario con 2 o 3 lóculos y 2 óvulos por cada lóbulo, estilo corto, estigma bi o trilobulado; fruto drupáceo, ovoide a subgloboso, biconvexo o más o menos asimétricamente trígono, tardíamente dehiscente por medio de 2 o 3 valvas, el hueso parcial o totalmente cubierto por un pseudoarilo que al abrirse el fruto es rojo, anaranjado o amarillo, pero por lo común pronto se torna gris o blanquecino; generalmente una semilla en cada fruto (Rzedowski et al., 2004).

Género con más de cien especies, distribuidas desde el sur de los Estados Unidos hasta Sudamérica, concentrando notablemente su diversidad en la vertiente pacífica de México. Muchas de ellas constituyen elementos dominantes o codominantes de la selva baja caducifolia. La resina aromática (copal) de varias especies se emplea a modo de incienso y el aceite esencial de B. linanoe (La Llave) Rzed., Calderón \& Medina, es el linaloe que se utiliza en la industria de los cosméticos y algunas artesanías. En diversas partes de México y de Centroamérica se usan árboles de Bursera para construir cercas vivas, ya que sus ramas convenientemente cortadas y enterradas producen nuevos individuos. Esta facilidad de reproducción por estacas representa una situación ventajosa que debería aprovecharse en acciones de reforestación.

\section{CLAVE PARA DETERMINACIÓN DE ESPECIES}

1 Hojas bipinnadas

B. bipinnata

1 Hojas pinnadas o trifolioladas.

2 Fruto trivalvado; flores trímeras, tetrámeras o pentámeras; corteza externa del tronco exfoliante.

3 Folíolos de hojas maduras de menos de $2.5 \mathrm{~cm}$ de largo; corteza externa del tronco amarillenta B. fagaroides 
3 Folíolos de hojas maduras de más de $2.5 \mathrm{~cm}$ de largo; corteza externa del tronco roja, anaranjada, pardo-rojiza a rojizo-amarillenta.

4 Folíolos 9 a 11, de margen entero …….............................. B. roseana

4 Folíolos 17 a 23, de margen serrado ................................ B. multijuga

2 Fruto bivalvado; flores tetrámeras; corteza externa del tronco no exfoliante.

5 Hojas blanco tomentosas en el envés, a veces glabrescentes con la edad; inflorescencia en forma de panícula espiciforme; pedúnculo de la infructescencia hasta de $1 \mathrm{~cm}$ de largo; folíolos agudos en el ápice ..... B. palmeri

5 Hojas sin tomento blanco en el envés; inflorescencia en forma de panícula laxa; pedúnculo de la infructescencia hasta de $13 \mathrm{~cm}$ de largo; folíolos caudado-atenuados en el ápice

B. penicillata

Bursera bipinnata (DC.) Engl., DC. Monogr. Phaner. 4: 49. 1883. Amyris bipinnata DC., Prodr. 2: 82. 1825. Elaphrium bipinnatum (DC.) Schltdl., Linnaea 17: 631. 1843. Terebinthus bipinnata (DC.) W. F. Wight ex Rose, Contr. U.S. Nat. Herb. 10: 119. 1906. Lectotipo: lámina 0715 de la colección Torner de ilustraciones de la expedición dirigida por Sessé y Mociño, designado por R. McVaugh en Botanical results of the Sessé \& Mociño expedition (1783-1803). VII. Guide to relevant scientific names of plants. p. 104. 2000. (Fig. 2 ).

Nombres comunes registrados en la zona de estudio: lantrisco, zocona.

Árbol o a veces arbusto dioico, hasta $8 \mathrm{~m}$ de alto, muy resinoso, con aroma agradable y penetrante al estrujarse, más o menos densamente pubérulo a subtomentoso y glabrescente en sus partes verdes; tronco hasta de $25 \mathrm{~cm}$ de diámetro, corteza gris a gris-rojiza, lisa, no exfoliante, las ramillas laterales cortas, agudas a menudo semejando espinas, glabras; hojas semejando frondas de helechos, a veces una vez pinnadas, pero con más frecuencia parcialmente bipinnadas y en ocasiones con tendencia a tripinnadas, pecíolo de 0.5 a $2 \mathrm{~cm}$ de largo, estriado, acanalado, lámina en contorno general de 2.5 a $8 \mathrm{~cm}$ de largo y 2 a $5 \mathrm{~cm}$ de ancho, con 3 a 8 pares de pinnas, con 1 a 8 pares de folíolos secundarios en la base y con 4 a 9 pares de folíolos primarios en la porción distal, raquis y raquillas angostamente alados, de borde entero, folíolos sésiles o subsésiles, de tamaño y forma muy variables a menudo en la misma hoja, lineares, oblongos, elípticos a ovados, obovados o suborbiculares, ápice redondeado a agudo, base cuneada, redondeada a ligeramente cordada, borde entero a trilobado, de 3 a $8 \mathrm{~mm}$ de largo y 2 a $7 \mathrm{~mm}$ de ancho, lustrosos en el haz, de textura cartácea, venación prominente en el envés, nervaduras secundarias distal- 

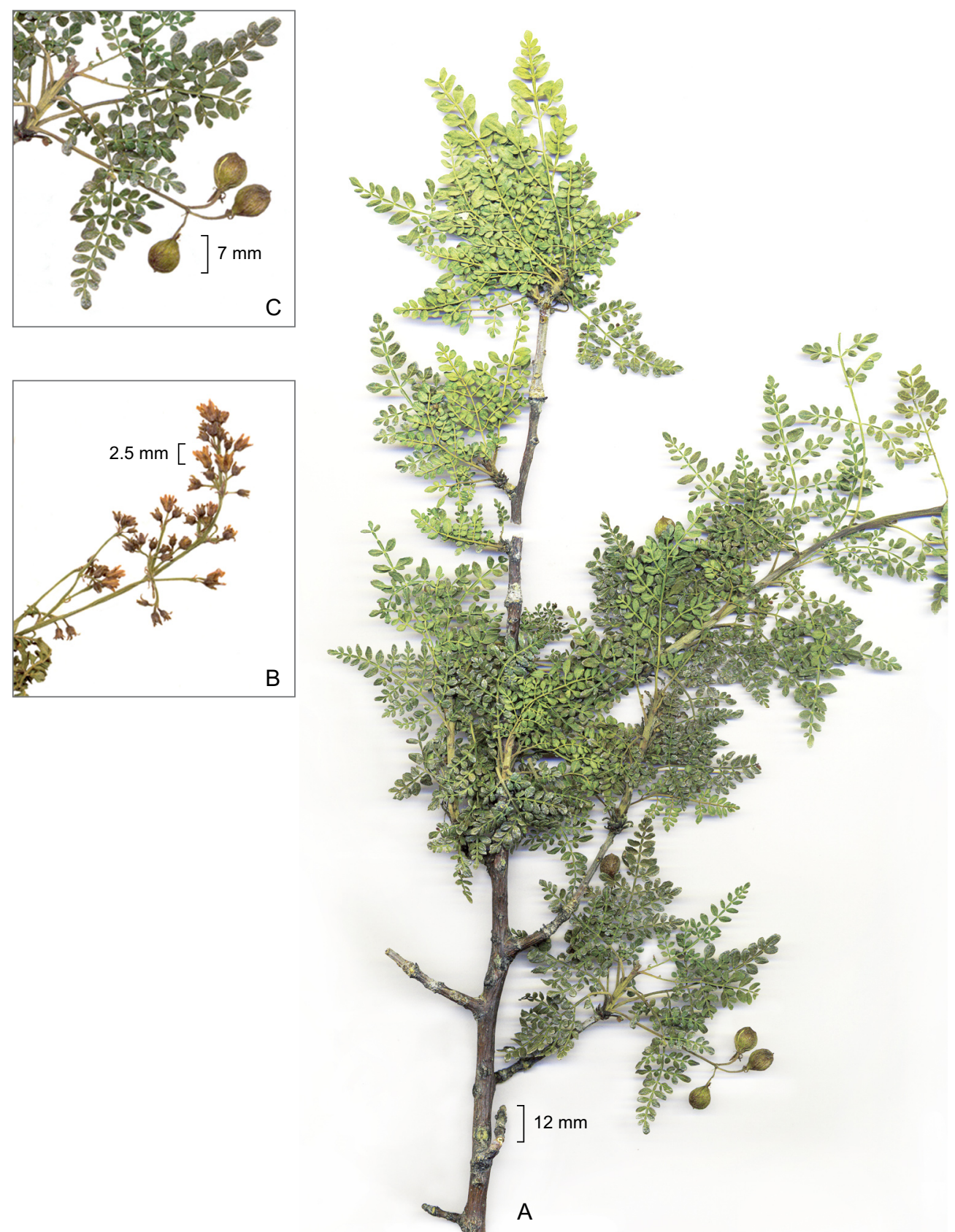
mente bifurcadas; catáfilos anchamente triangulares a lanceolados, agudos, de 2 a 4 $\mathrm{mm}$ de largo y $2 \mathrm{~mm}$ de ancho, pardo-rojizos, pubescentes, precozmente decíduos; inflorescencias racimosas a paniculiformes, de 2 a $6 \mathrm{~cm}$ de largo, pubérulas, bractéolas subuladas, de $2 \mathrm{~mm}$ de largo, pedicelos de 1 a $2 \mathrm{~mm}$ de largo; flores masculinas tetrámeras, lóbulos del cáliz angostamente triangulares, de 1.5 a $2 \mathrm{~mm}$ de largo y de $0.5 \mathrm{~mm}$ de ancho, a veces excediendo a los pétalos, pubérulos en ambas caras, pétalos blanquecinos a amarillentos o verdosos, oblanceolados, de 1.8 a $2.5 \mathrm{~mm}$ de largo y $0.7 \mathrm{~mm}$ de ancho, más o menos cuculados en el ápice ligeramente reflejos en la madurez, pubérulos por fuera principalmente a lo largo de la costa, estambres 8 , subiguales, dispuestos en dos series, filamentos de 0.8 a $1 \mathrm{~mm}$ de largo, anteras ovado-oblongas, de 0.4 a $0.5 \mathrm{~mm}$ de largo; flores femeninas similares en forma y tamaño, a veces con los pétalos un poco más cortos que los sépalos, ovario bilocular, glabro, estigmas 2, estaminodios inconspicuos, disco con 8 lóbulos; infructescencias de 4 a $6 \mathrm{~cm}$ de largo con 1 a varios frutos sobre pedúnculos de 1 a $2.5 \mathrm{~cm}$ de largo, bivalvados, ovoides, de 6 a $8 \mathrm{~mm}$ de largo y 4 a $5 \mathrm{~mm}$ de ancho, hueso de 5 a 6 $\mathrm{mm}$ de largo y 3.5 a $4 \mathrm{~mm}$ de diámetro, algo comprimido, negro en la parte expuesta, recubierto casi totalmente por un pseudoarilo rojo en la madurez.

Esta planta se encuentra en selva baja caducifolia y con menor frecuencia en la zona de transición de éste con el bosque de Quercus en altitudes de 1650-1950 m. De las especies localizadas en el estado es una de las menos abundantes. Se colectó con flor y primeras hojas en mayo y junio; con fruto de julio a octubre. Localmente se utiliza la resina en emplastos para problemas de hernias.

Con distribución de México y Centroamérica. En México se conoce de Aguascalientes, Chiapas, Chihuahua, Colima, Durango, Guerrero, Guanajuato, Jalisco, México, Michoacán, Morelos, Nayarit, Oaxaca, Puebla, Sinaloa, Veracruz y Zacatecas.

Ejemplares examinados: municipio Calvillo. Barranca Cebolletas, oeste de la Presa Calvillo, 21 ${ }^{\circ} 52^{\prime} 35^{\prime \prime} \mathrm{N}$; 102³0'31" W, de la Cerda 7151 (HUAA, IEB); Presa Tres Cruces, de la Cerda 7179 (HUAA, INEGI, QMEX); suroeste Presa Los Serna, camino a La Luz, 2147'35" N; 10250'49" W, de la Cerda 7269, 7299 (CIIDIR, HUAA); $1.2 \mathrm{~km}$ al suroeste de Presa Los Serna, García G. 4798 (HUAA); extremo oeste de la Presa Malpaso, de la Cerda y García G. 1492 (HUAA); barranca Los Adobes, García G. 4683 (HUAA) (Fig. 5). 
Bursera fagaroides (H.B.K.) Engl., Bot. Jahrb. Syst. 1: 41. 1881. Elaphrium fagaroides H.B.K., Nov. Gen. \& Sp. 7: 27. t. 611. 1824. Amyris fagaroides (H.B.K.) Spreng., Syst. Veg. 4: 148. 1827. Terebinthus fagaroides (H.B.K.) Rose, Contr. U.S. Nat. Herb. 10: 119. 1906. Tipo: México, Querétaro, A. Humboldty A. Bonpland 4200 (holotipo P). (Fig. 3).

Nombre común registrado en la zona de estudio: venadilla.

Árbol o arbusto, dioico o a veces hermafrodita, de 0.5 a $8 \mathrm{~m}$ de alto, glabro, ramillas jóvenes con abundante resina transparente poco aromática; tronco hasta de 30 cm de diámetro, con corteza externa exfoliante en láminas delgadas de color amarillogrisáceo, las capas internas a menudo verde-azulosas a glaucas, látex blanquecino o amarillento; hojas imparipinnadas (excepcionalmente trifolioladas o simples), pecíolo de 0.5 a $2.5 \mathrm{~cm}$ de largo, raquis con alas inconspicuas, con 3 a 5 pares de folíolos, sésiles o subsésiles excepto a veces el terminal, que puede llevar un peciólulo hasta de $1 \mathrm{~cm}$ de largo, de forma elíptica, oblonga a obovada o suborbicular, de 1 a $3.5 \mathrm{~cm}$ de largo y de 1 a $2 \mathrm{~cm}$ de ancho, aumentando de tamaño hacia el extremo distal de la hoja, ápice obtuso a agudo, base cuneada, pero a veces obtusa o redondeada, borde entero, crenado o serrado, de textura membranácea firme, la nervadura central conspicua en el envés, por lo general amarillenta, las laterales más o menos 6 pares, más débilmente marcadas; catáfilos morenos, inconspicuos, pronto decíduos; las flores generalmente solitarias o a veces agrupadas en inflorescencias cortas, aglomeradas densamente en las puntas de ramillas cortas; flores masculinas pentámeras, algunas veces trímeras o tetrámeras, lóbulos del cáliz angostamente triangulares, agudos, glandular-dentados, verdes con tintes rojizos, de 1 a $2 \mathrm{~mm}$ de largo, pétalos verdosos a blanco-amarillentos, oblongos a oblongo-oblanceolados, de 3 a $6 \mathrm{~mm}$ de largo, cuculados, ápice incurvado, reflejos en la madurez, estambres subiguales, filamentos de $1 \mathrm{~mm}$ de largo, anteras oblongas, de $1.5 \mathrm{~mm}$ de largo, disco verde, glutinoso; las flores femeninas similares en forma y tamaño, casi siempre trímeras, estaminodios de $1 \mathrm{~mm}$ de largo, ovario trilocular, estigmas 3 ; infructescencia con pedúnculos cortos de 1 a varios frutos, pedúnculos del fruto de 0.5 a $3 \mathrm{~mm}$ de largo, algo incurvados y engrosados, fruto trivalvado, obovoide a subesférico, cortamente apiculado, rojizo, de 0.5 a $0.8 \mathrm{~cm}$ de largo, el hueso recubierto totalmente por un pseudoarilo rojizo a amarillento en la madurez.

Es el representante con más amplia distribución del género en el área de estudio y también el más abundante. Se localiza con frecuencia en diferentes tipos de matorrales como el espinoso, subespinoso, subinerme, matorral subtropical-encino, 
de la Cerda-Lemus: La familia Burseraceae en el estado de Aguascalientes, México

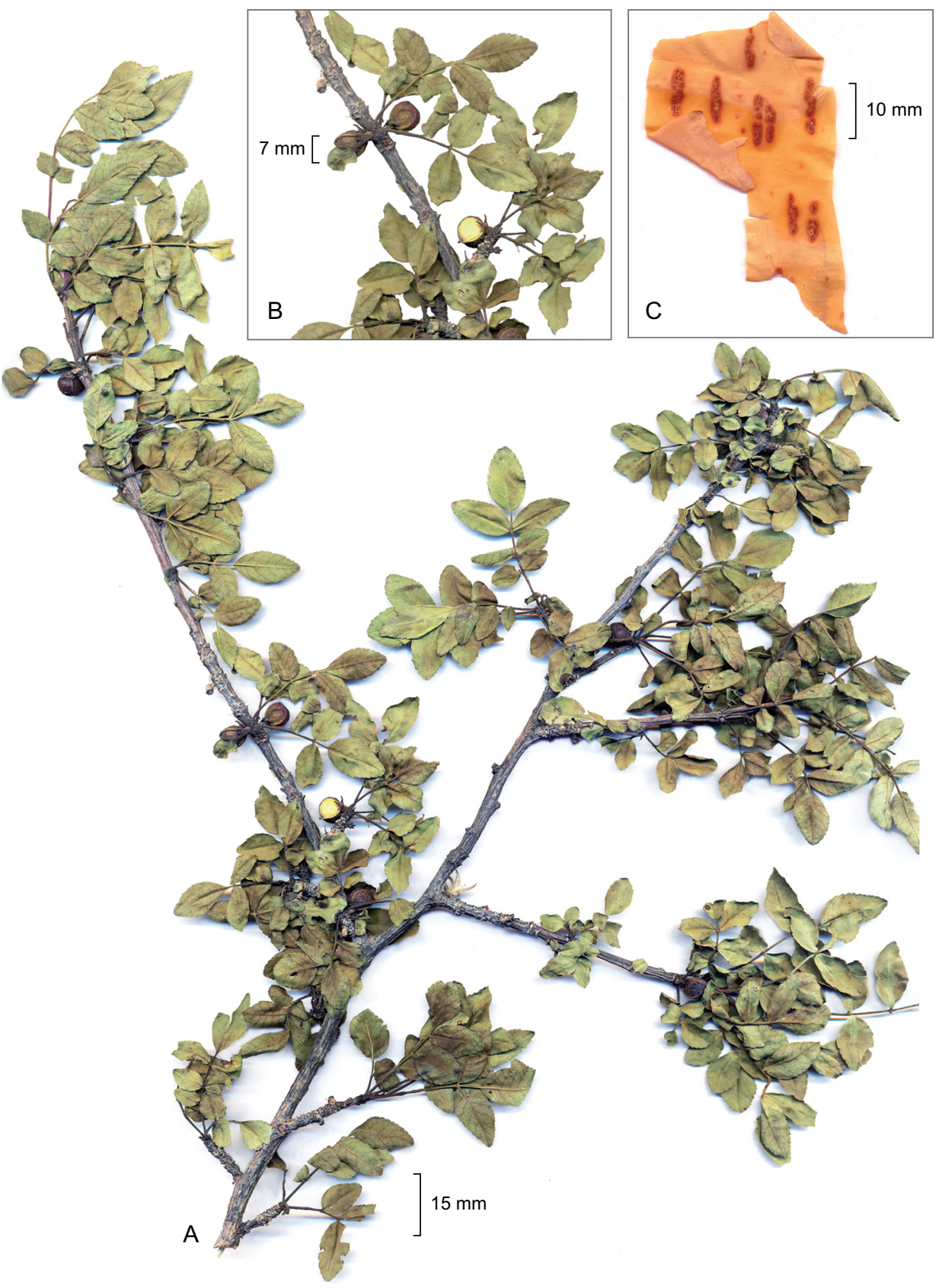

Fig. 3. Bursera fagaroides. A. rama con frutos; B. frutos; C. detalle de la corteza externa. 
selva baja caducifolia-bosque de encino. Alt. 1690-2500 m. Se encuentra con flor en abril y mayo y con frutos de julio a noviembre; se utiliza para cercas vivas en forma de postes y para sostener alambres.

Se conoce su distribución desde el suroeste de los Estados Unidos hasta Oaxaca en México.

Ejemplares examinados: municipio Aguascalientes. Ladera norte cerro Los Gallos, de la Cerda y García G. 21 (HUAA); ladera sur del cerro Juan El Grande, de la Cerda 3175 (HUAA); ladera noroeste del cerro del Picacho, de la Cerda y García G. 1023 (HUAA). Municipio Asientos. Ejido Los Encinos, cerro El Estaño, Siqueiros 2240 (HUAA). Municipio Calvillo. 2 miles (c. $3 \mathrm{~km}$.) S of Calvillo, McVaugh \& Koelz 61 (MEXU); $5 \mathrm{~km}$ al sureste de Malpaso, de la Cerda y García G. 346 (ENCB, HUAA); $4 \mathrm{~km}$ al este de Piedras Chinas, de la Cerda y García G. 839 HUAA, MEXU); $1 \mathrm{~km}$ a la salida del libramiento Calvillo-Jalpa $21^{\circ} 50^{\prime} 33^{\prime \prime} \mathrm{N} ; 102^{\circ} 41^{\prime} 43^{\prime \prime} \mathrm{W}$,

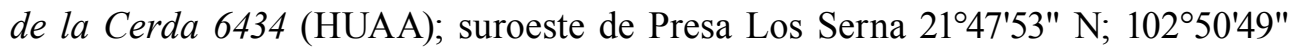
W, de la Cerda 7267 (HUAA, QMEX); sureste Presa Los Serna, de la Cerda 7102 (CIIDIR, HUAA); Presa Tres Cruces, de la Cerda 7180 (HUAA, INEGI); oeste de la cortina de la Presa Malpaso, de la Cerda 7187 (HUAA); barranca Cebolletas

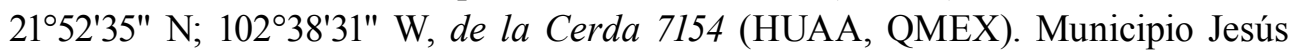
María. Mesa La Palma, de la Cerda y García G. 649 (HUAA). Municipio San José de Gracia. Sierra Fría, 12 km NW de San Antonio de los Ríos, R. Fernández N. 1635 (MEXU); $4 \mathrm{~km}$ al este de La Congoja, de la Cerda y García G. 43 (HUAA); $1 \mathrm{~km}$ al noroeste de la Presa Jocoqui, de la Cerda y García G. 1069 (HUAA); Estación Biológica Agua Zarca, Rosales O. 2077 (CIIDIR, HUAA) (Fig. 5).

Bursera multijuga Engl., Monogr. Phaner. 4: 42. 1883. (Tipo: México, Colima, $E$. Kerber $s / n$. (B, probablemente perdido), Bursera pringlei S. Watson. Proc. Amer. Acad. 25: 145. 1890. Terebinthus rubra Rose Contr. U.S. Nat. Herb. 10: 121. 1906. Elaphrium multijugum (Engl.) Rose N. Amer. Fl. 25: 248. 1911. Bursera rubra (Rose) Riley, Bull. Misc. Inf. Kew 1923: 168. 1923. (Fig. 4).

Nombre común registrado en la zona de estudio: palo colorado.

Árbol hasta de $12 \mathrm{~m}$ de alto, resinoso y poco aromático, glabro, tronco hasta de $30 \mathrm{~cm}$ de diámetro, con corteza externa exfoliante en láminas delgadas de color pardo-rojizo, las capas internas más delgadas y a menudo de color rojizo-amarillento 
de la Cerda-Lemus: La familia Burseraceae en el estado de Aguascalientes, México

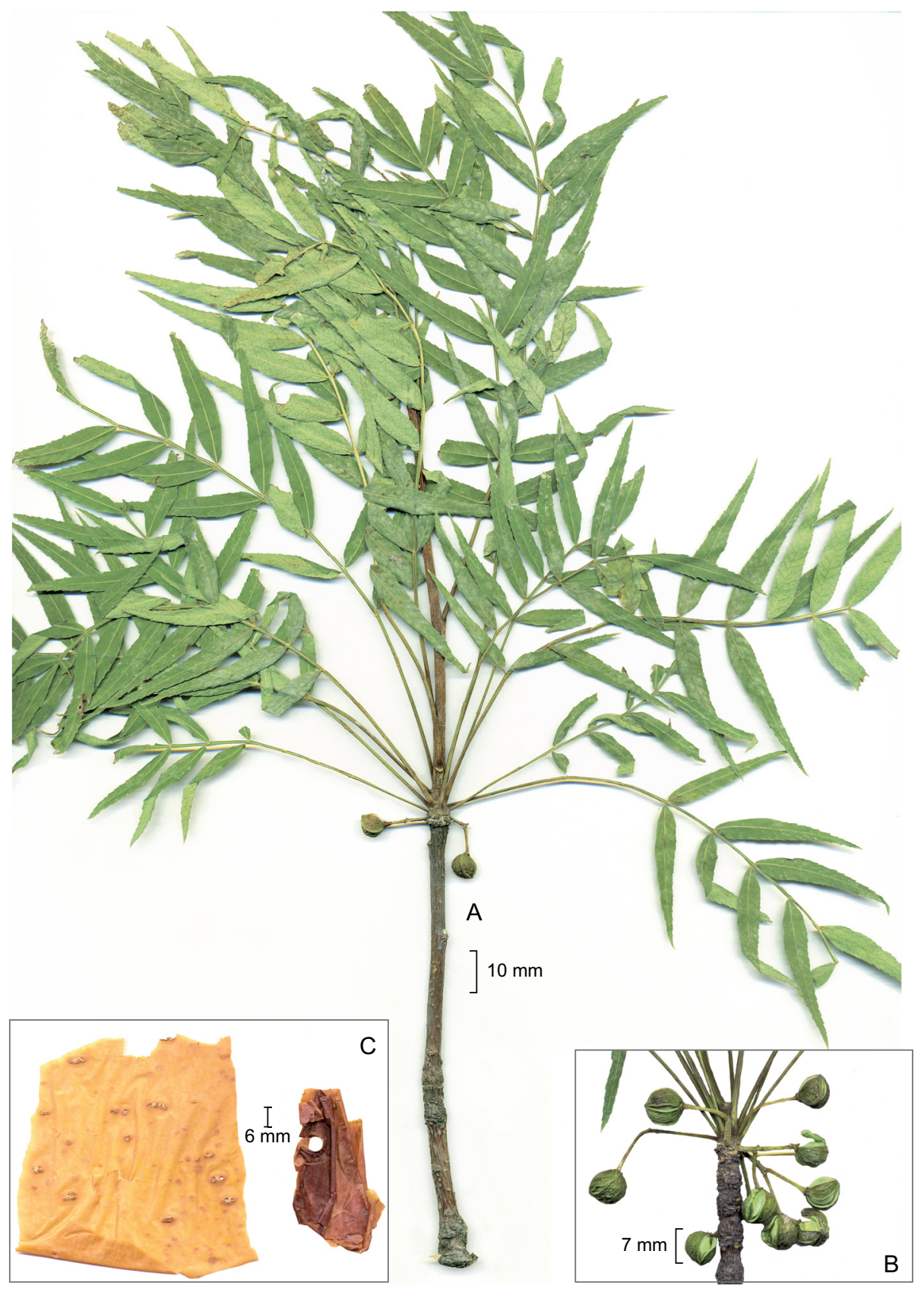

Fig. 4. Bursera multijuga. A. rama con frutos; B. frutos; C. detalle de corteza externa. 
claro, con resina amarillenta, transparente, poco aromática; ramillas jóvenes glabras, de color pardo-rojizo, con abundantes lenticelas anaranjadas; hojas imparipinnadas, pecíolo de 2.5 a $3 \mathrm{~cm}$ de largo, raquis angostamente alado, ampliándose ligeramente hacia los folíolos terminales, con 17 a 23 folíolos, sésiles, de forma angostamente lanceolada, de 3 a $4.5 \mathrm{~cm}$ de largo y 0.5 a $0.7 \mathrm{~cm}$ de ancho, haciéndose más angostos hacia el extremo distal, ápice agudo, base redondeada a ligeramente cuneada, borde serrado, algunos folíolos con margen entero hacia la mitad inferior de ambos o uno

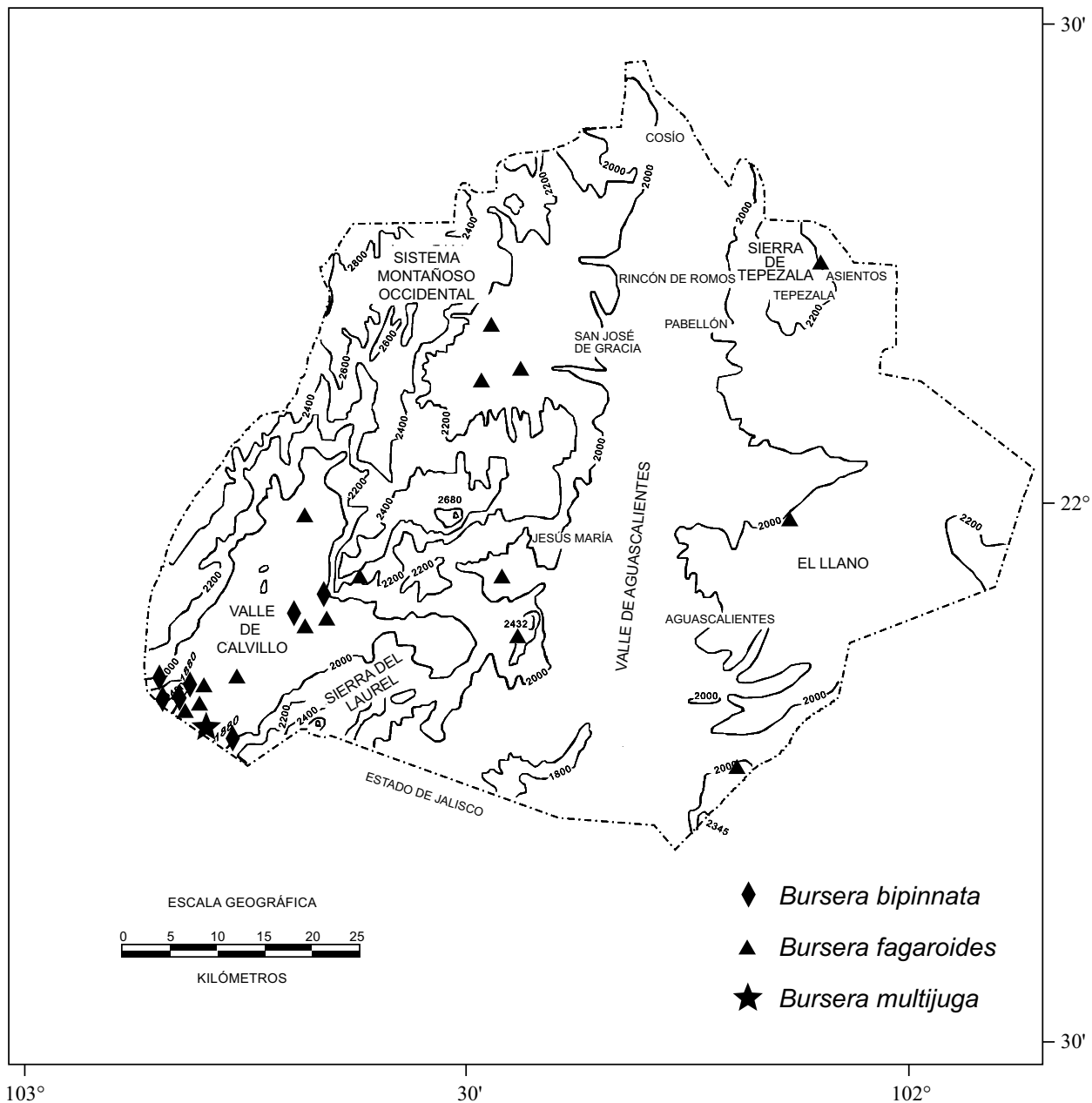

Fig. 5. Distribución de Bursera bipinnata, B. fagaroides y B. multijuga. 
de los lados, de textura membranácea, ligeramente pubérulos en el envés, la nervadura central conspicua en ambos lados, las nervaduras laterales débilmente marcadas, muy ramificadas, haz verde brillante, envés ligeramente glauco-amarillento; inflorescencias en panículas de 1.5 a $3.5 \mathrm{~cm}$ de largo en las axilas de las hojas terminales, bractéolas de $2 \mathrm{~mm}$ de largo, pedicelos de 2 a $3 \mathrm{~mm}$; flores masculinas pentámeras, sépalos triangulares, de $1.5 \mathrm{~mm}$ de largo, pétalos amarillento-verdosos, oblongos, de $5 \mathrm{~mm}$ de largo por $1.5 \mathrm{~mm}$ de ancho, estambres subiguales, filamentos de $1 \mathrm{~mm}$ de largo, anteras de $1.2 \mathrm{~mm}$ de largo, disco anular; flores femeninas similares a las masculinas con estaminodios presentes, ovario trilocular; pedúnculo del fruto de 6 a $14 \mathrm{~mm}$ de largo, algo curvo, fruto trivalvado, subesférico con un lado más curvo, con un pequeño mucrón, pardo oscuro en la madurez, de 6 a $8 \mathrm{~mm}$ de largo, el hueso recubierto totalmente por un pseudoarilo verdoso a pardo-amarillento al madurar.

Se encontró únicamente en una localidad en el municipio de Calvillo, en selva baja caducifolia-pastizal. Alt. $1840 \mathrm{~m}$. Se encuentra con fruto de agosto a noviembre.

Se conoce su distribución de Aguascalientes, Colima, Durango, Jalisco, Michoacán, Nayarit, Sinaloa y Zacatecas.

Ejemplares examinados: municipio Calvillo. El Huencho, Jaltiche de Arriba, Esparza L. 261 (CIIDIR, HUAA, INEGI); El Huencho, 21²4'16" N; 10247'17" W, de la Cerda 7338 (HUAA, IEB) (Fig. 5).

Bursera palmeri S. Watson, Proc. Amer. Acad. Arts 22: 402. 1887. (Tipo: México, Jalisco, Río Blanco, V-X.1886. E. Palmer 609 (GH), isotipo en US). Elaphrium palmeri (S. Watson) Rose, N. Amer. Fl. 25: 255. 1911. Elaphrium queretarense Rose, N. Amer. Fl. 25: 254. 1911. (Fig. 6).

Nombre común registrado en la zona de estudio: copalillo.

Árbol a veces arbusto dioico, hasta de $8 \mathrm{~m}$ de alto, muy resinoso, con aroma fuerte y agradable al estrujarse, tomentoso en todas las partes tiernas; tronco hasta de $30 \mathrm{~cm}$ de diámetro, corteza gris o gris rojiza, no exfoliante, las ramillas lignificadas, rojizas, glabras; hojas con 3 a 9 folíolos, el pecíolo por lo general un poco más corto que los folíolos, pero más largo que los entrenudos del raquis, tomentosohíspido, el raquis manifiestamente alado, las alas a veces dentadas, folíolos subsésiles, ovados a lanceolados o a veces oblongos, de 2.5 a $6 \mathrm{~cm}$ de largo y 0.7 a $3 \mathrm{~cm}$ de 
Acta Botanica Mexicana 94: 1-25 (2011)

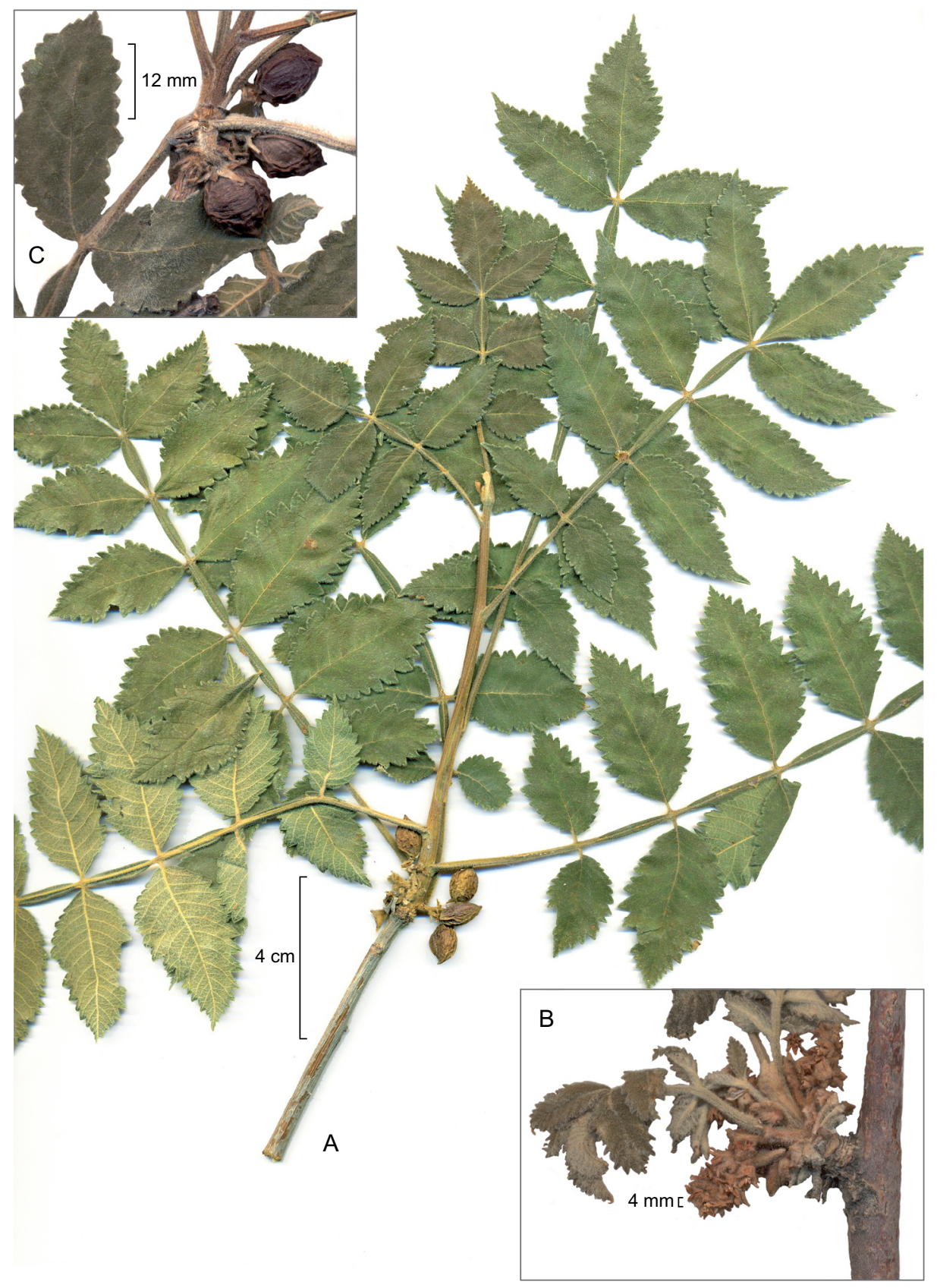

Fig. 6. Bursera palmeri. A. rama con frutos; B. detalle de las flores masculinas; C. frutos. 
ancho, los del par inferior comúnmente más pequeños que los demás, por lo general agudos, pero variando de obtusos a acuminados en el ápice, redondeados y algo oblicuos (los laterales) a cuneados en la base, margen toscamente aserrado a dentado, con 10 a 20 pares de nervaduras laterales distalmente bifurcadas, más prominentes en el envés, membranáceos, densamente tomentosos y blanquecinos en la juventud, a veces glabrescentes con la edad en el envés, tomentoso-híspido en el haz, que siempre es más oscuro; catáfilos oblongos a obtriangular-flabelados, de 4 a $9 \mathrm{~mm}$ de largo, verdes, tomentosos por fuera, glabros por dentro, precozmente decíduos; inflorescencias originándose en los ápices de ramas cortas o lateralmente en ramas largas, con las flores densamente agrupadas, con frecuencia semejando glomérulos, las flores masculinas en panículas espiciformes hasta de 5 a $8 \mathrm{~cm}$ de largo, con las flores muy apretadas en forma de glomérulos o verticilastros, pedúnculos hasta de $3.5 \mathrm{~cm}$ de largo, pedicelos ausentes, bractéolas subuladas, de $2 \mathrm{~mm}$ de largo, flores tetrámeras, lóbulos del cáliz angostamente deltoides, de $2 \mathrm{~mm}$ de largo, agudos en el ápice, densamente blanco-tomentosos, pétalos blanquecinos, tornándose pardos, oblanceolados, de 3 a $4 \mathrm{~mm}$ de largo, más o menos cuculados, blanco tomentosos por fuera, glabros por dentro, estambres todos aproximadamente al mismo nivel, filamentos de aproximadamente $2 \mathrm{~mm}$ de largo, anteras ovado-oblongas, de 1 a 1.2 $\mathrm{mm}$ de largo; las inflorescencias femeninas similares, pero de solo $1 \mathrm{a} 2 \mathrm{~cm}$ de largo, con los pétalos de más o menos $2 \mathrm{~mm}$ de largo, un poco más cortos que los segmentos del cáliz, estaminodios con anteras de $0.8 \mathrm{~mm}$ de largo, ovario bilocular, glabro o pubérulo; infructescencias en forma de glomérulos o bien los frutos solitarios, sobre pedúnculos de 1 a $3 \mathrm{~cm}$ de largo, fruto bivalvado, verde a rojizo, elipsoide, ovoide o subesférico, de 10 a $14 \mathrm{~mm}$ de largo, a menudo puntiagudo en el ápice, glabro o pubérulo, rodeado en la base por el cáliz persistente, el hueso recubierto parcialmente por un pseudoarilo rojizo, anaranjado o amarillento en la madurez.

En la entidad fue encontrada en selva baja caducifolia, selva baja caducifoliaencino, matorral subinerme-pastizal y en vegetación secundaria. Alt. 1600-2200 m. Se le encuentra con flores en mayo y junio, con fruto de julio a septiembre.

Se conoce su distribución de Aguascalientes, Durango, Guanajuato, Jalisco, Michoacán, Querétaro y Zacatecas.

Ejemplares examinados: municipio Aguascalientes. Extremo norte del cerro del Picacho, de la Cerda y García G. 1554 (HUAA). Municipio Calvillo. 9 km noreste de Calvillo, sobre la carretera a Aguascalientes, Rzedowski \& McVaugh 
1255 (MEXU); 4 km al noroeste de Barranca Oscura, de la Cerda y García G. 106 (HUAA); $2 \mathrm{~km}$ al noreste de Palo Alto, García G. 2510 (HUAA); $4 \mathrm{~km}$ al noroeste del Temascal 22 $011^{\prime} 47^{\prime \prime} \mathrm{N} ; 102^{\circ} 44^{\prime} 58^{\prime \prime} \mathrm{W}$, de la Cerda 6213 (HUAA); $4 \mathrm{~km}$ al este de Piedras Chinas, de la Cerda y García G. 831 (HUAA); barranca Tortugas, de la Cerda y García G. 1655 (CIIDIR, HUAA); barranca Montoro, García G, 3270 (HUAA);

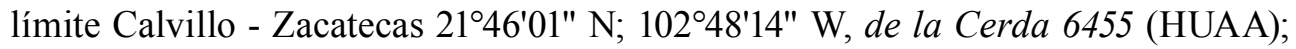
$0.5 \mathrm{~km}$ al oeste de Los Alisos, García G. 5027 (HUAA); Presa Tres Cruces, de la Cerda 7175 (HUAA, INEGI); límite Aguascalientes - Zacatecas por la salida a Jalpa, 214'43" N; 10248'18" W, de la Cerda 7194 (CIIDIR, HUAA); barranca Cebolletas 21 ${ }^{\circ} 52^{\prime} 35^{\prime \prime} \mathrm{N}$; 102 $38^{\circ} 31^{\prime \prime} \mathrm{W}$, de la Cerda 7152 (HUAA, QMEX); La Fragua

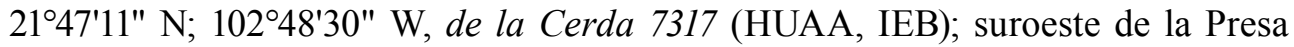
Los Serna $21^{\circ} 47^{\prime} 53^{\prime \prime} \mathrm{N}$; 102 ${ }^{\circ} 50^{\prime} 49^{\prime \prime} \mathrm{W}$, de la Cerda 7270 (HUAA); sureste Presa Los Serna, de la Cerda 7096 (CIIDIR, HUAA). Municipio San José de Gracia. 1 km al oeste de la Presa Jocoqui, de la Cerda 2468 (HUAA, MEXU); El Huencho 21\%44'47" N; 10246'47" W, de la Cerda 7337 (HUAA) (Fig. 9).

Bursera penicillata (DC.) Engl., Bot. Jahrb. 1: 44. 1881. Elaphrium penicillatum DC., Prodr. 1: 724. 1824. (Tipo: A. DC. Calq. Dess. Fl. Mex. 213). Bursera graveolens $\beta$ pilosa Engl., DC., Monogr. Phaner. 4: 49. 1883. Bursera mexicana Engl., Monogr. Phaner. 4: 5. 1883. Bursera inopinata Bullock Bull. Misc. Inf. Kew 1937: 456. 1937. (Fig. 7)

Nombres comunes registrados en la zona de estudio: árbol de chicle, mostoche.

Árbol dioico, rara vez polígamo-dioico, hasta de $12 \mathrm{~m}$ de alto, muy resinoso, con aroma fuerte y agradable a trementina, al estrujarse; tronco hasta de 40 $\mathrm{cm}$ de diámetro, corteza lisa, no exfoliante, gris a gris-rojiza, las ramillas rojizas, lustrosas; hojas de 15 a $26 \mathrm{~cm}$ de largo, con 3 a 15 folíolos, pecíolo de 5 a $6 \mathrm{~cm}$ de largo, estriado-acanalado, raquis manifiestamente alado, más ancho hacia la porción distal, a veces las alas inconspicuas entre el primer y segundo par de folíolos, entrenudos de 2 a $2.8 \mathrm{~cm}$ de largo, a veces escasamente dentado, a menudo con un inconspicuo mechón de pelos en los nudos, folíolos sésiles, angostamente lanceolados a ovado-lanceolados, de 4 a $8 \mathrm{~cm}$ de largo y 1 a $4 \mathrm{~cm}$ de ancho, subiguales o bien los pares intermedios un poco mayores, caudado-acuminados en el ápice, con la punta redondeada, base cuneada, borde dentado-serrado con 5 a 10 dientes anchos y redondeados a agudos de cada lado, el folíolo terminal con frecuencia más ancho 
de la Cerda-Lemus: La familia Burseraceae en el estado de Aguascalientes, México

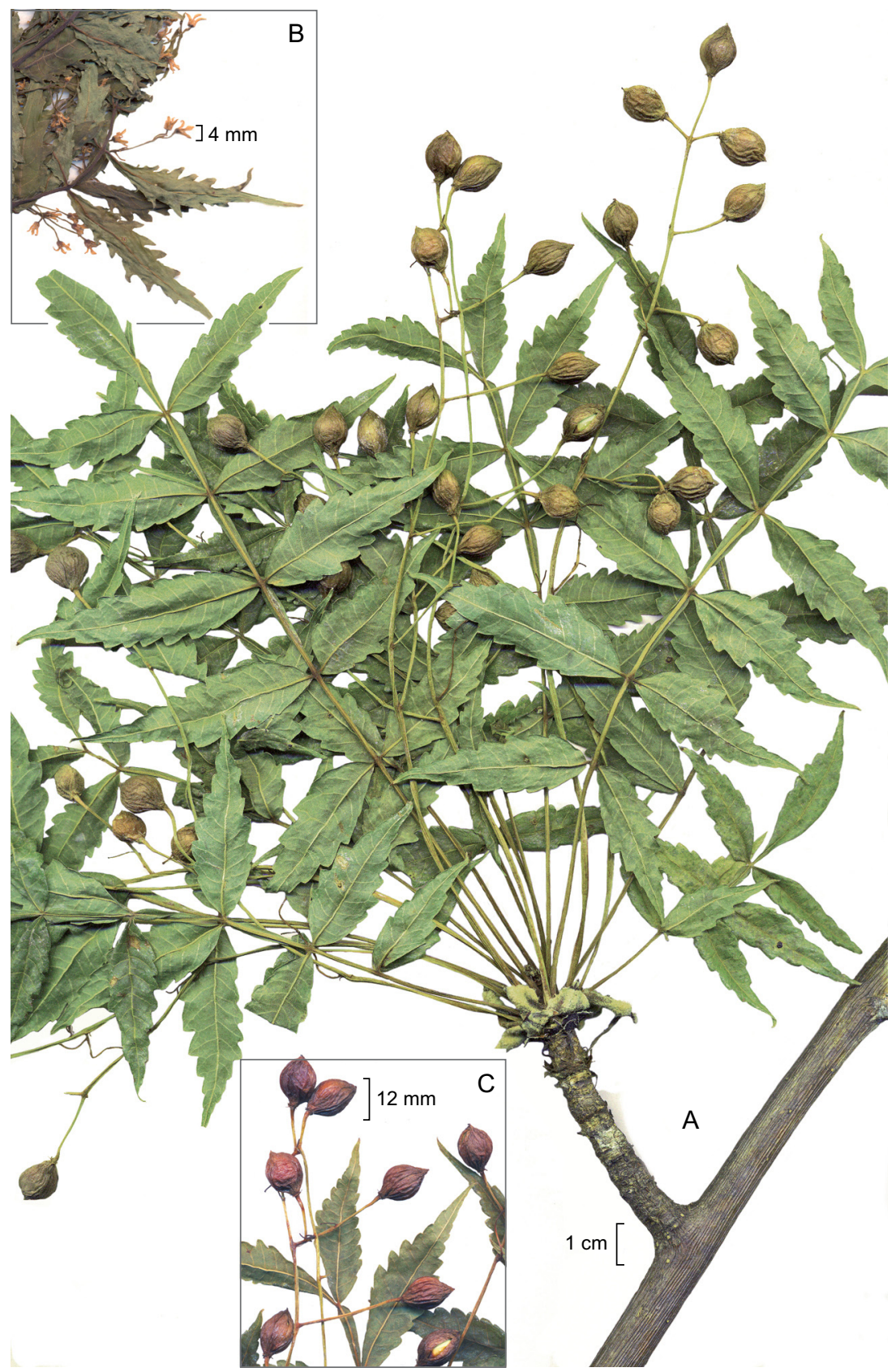

Fig. 7. Bursera penicillata. A. rama con frutos; B. detalle de la inflorescencia; C. frutos. 
que los laterales y con la base largamente cuneada, con 8 a 12 pares de nervaduras secundarias distalmente bifurcadas, prominentes en el envés, de textura membranácea firme, brillantes en el haz, la pubescencia de las hojas es variable, aún en el mismo individuo, pues éstas pueden ser completamente glabras o llevar pilosidad escasa o abundante, principalmente en el pecíolo, en el raquis y envés de los folíolos, el borde de estos últimos varía de más o menos ciliado a desprovisto de pelos; catáfilos subpersistentes, dispuestos en varias series, los externos triangular-ovados y de más o menos $5 \mathrm{~mm}$ de largo, los de las series internas oblongos a ovados, hasta de 2 $\mathrm{cm}$ de largo y $8 \mathrm{~mm}$ de ancho, ferrugíneo-tomentosos por fuera; inflorescencias paniculadas, tirsiformes o pseudoracimosas, de 4 a $13 \mathrm{~cm}$ de largo, sobre pedúnculos hasta de $7 \mathrm{~cm}$ de largo, eje de la inflorescencia glabro y con mechoncitos de pelos en los nudos a subtomentosos, bracteólas filiformes, por lo general precozmente caducas, pedicelos de 3 a $5 \mathrm{~mm}$ de largo; flores masculinas tetrámeras, lóbulos del cáliz triangulares, de 0.5 a $1 \mathrm{~mm}$ de largo y $0.5 \mathrm{~mm}$ de ancho, casi glabros a densamente pubescentes, pétalos blanquecinos, oblongos a oblanceolados, cuculados, de 3 a 4 $\mathrm{mm}$ de largo y $1 \mathrm{~mm}$ de ancho, conspicuamente hirsuto-pubérulos a lo largo de la parte media a densamente hirsútulos por fuera, estambres subiguales, filamentos de 1.2 a $1.5 \mathrm{~mm}$ de largo, anteras oblongas, de $1 \mathrm{~mm}$ de largo; flores femeninas similares a las masculinas, ovario bilocular, glabro o pubescente, estigma bilobulado, anteras de los estaminodios de más o menos $0.5 \mathrm{~mm}$ de largo, disco con 8 lóbulos; infructescencias de 8 a $18 \mathrm{~cm}$ de largo, sobre pedúnculos de 3 a $8 \mathrm{~cm}$ de largo, aplanados, fruto bivalvado, obovoide, a menudo apiculado, algo comprimido, de 10 a 13 $\mathrm{mm}$ de largo y 8 a $10 \mathrm{~mm}$ de ancho, verde a rojizo, glabro, rodeado en la base por el cáliz persistente, hueso obovoide a subesférico, con una cara más convexa que la otra, recubierto parcialmente por un pseudoarilo rojizo, anaranjado o pálido en la madurez, la cara más convexa cubierta en su tercio basal, la otra hasta cerca de la mitad y los cantos hasta cuatro quintos de su altura.

Habita principalmente en la selva baja caducifolia y matorral subtropical. Alt. 1810-1950 m. Florece de mayo a junio, fructifica en julio y agosto y permanece con follaje de mayo a noviembre.

Se conoce su distribución de Aguascalientes, Chihuahua, Colima, Durango, Guanajuato, Jalisco, Michoacán, Nayarit, Sinaloa, Sonora y Zacatecas.

Ejemplares examinados: municipio Calvillo. Road to Calvillo, W. of Aguascalientes near km 40, McVaugh 18320 (ENCB, MICH); Malpaso, Calvillo, Ags., Vic- 
tor Manuel Silva 33 (MEXU); $9 \mathrm{~km}$ noreste de Calvillo, sobre la carretera a Aguascalientes, Rzedowski y McVaugh 1260 (MEXU); suroeste de la Presa Los Serna,

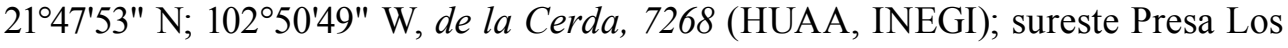
Serna, de la Cerda 7099 (HUAA); barranca Cebolletas 2152'35" N; 102 $38^{\prime} 31^{\prime \prime} \mathrm{W}$, de la Cerda 7148 (HUAA, INEGI); oeste de la cortina de la Presa Malpaso, 2151'43" N; 102³9'11" W, de la Cerda 7190 (HUAA, IEB); Presa La Codorniz 2159'44" N; 10240'37" W, de la Cerda 7025 (CIIDIR, HUAA); 2 km al noroeste del Tepozán,

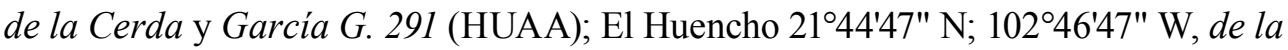
Cerda 7331 (HUAA) (Fig. 9).

Bursera roseana Rzed., Calderón \& Medina, Acta Bot. Mex. 81: 45. 2007 (nombre basado en Terebinthus acuminata Rose). Terebinthus acuminata Rose, Contr. U.S. Natl. Herb. 12: 278. 1909. Elaphrium acuminatum (Rose) Rose, N. Amer. Fl. 25: 247. 1911. Bursera acuminata (Rose) Engl., Natur. Pflanzenfam. ed. 2. 19a: 425. 1931, non B. acuminata Willd., 1806. (Tipo: México, Jalisco, near Chapala, 5.X.1903, J. N. Rose y J. H. Painter 7656, holotipo US, isotipo NY). (Fig. 8).

Nombre común registrado en la zona de estudio: cebolleta.

Árbol hasta de $12 \mathrm{~m}$ de alto, aparentemente dioico, poco aromático y resinoso; con tronco hasta de $25 \mathrm{~cm}$ de diámetro, corteza roja, anaranjada o pardo-rojiza, ramillas tiernas a menudo densamente vilosas al inicio, pero perdiendo rápidamente todos o casi todos los pelos, otras veces glabras desde el principio; hojas originándose sobre ramillas de crecimiento nuevo, imparipinnadas, hasta de $45 \mathrm{~cm}$ de largo y $22 \mathrm{~cm}$ de ancho, pecíolo hasta de $12 \mathrm{~cm}$ de largo, raquis sin alas, peciólulo terminal hasta de $4 \mathrm{~cm}$ de largo, los laterales de 1 a $9 \mathrm{~mm}$ de largo, de $1 \mathrm{~mm}$ o un poco más de ancho, folíolos (3)5 a 7(9), ovados a elípticos, el terminal a veces obovado o subrómbico, de 4.5 a $15 \mathrm{~cm}$ de largo, de 2 a $6 \mathrm{~cm}$ de ancho, ápice abrupta y largamente acuminado, base cuneada a truncada, a menudo inequilátera, margen entero, nervaduras secundarias 5 a 12 pares, arqueadas, las terciarias formando un retículo, de textura membranácea o cartácea, brillantes y glabros o casi glabros desde la juventud en el haz, opacos y pilosos o pilósulos sobre las nervaduras en el envés, al menos en la juventud, a veces completamente glabros en la madurez; inflorescencias en forma de panículas piramidales angostas (a veces las femeninas reducidas a racimos), hasta de $13 \mathrm{~cm}$ de largo y $5 \mathrm{~cm}$ de diámetro, glabras, brácteas lineares a lanceoladas, de 1.5 a $2 \mathrm{~mm}$ de largo, caedizas, pedicelos filiformes, hasta de $8 \mathrm{~mm}$ de largo; flores masculinas pentámeras o a veces tetrámeras, segmentos del cáliz 


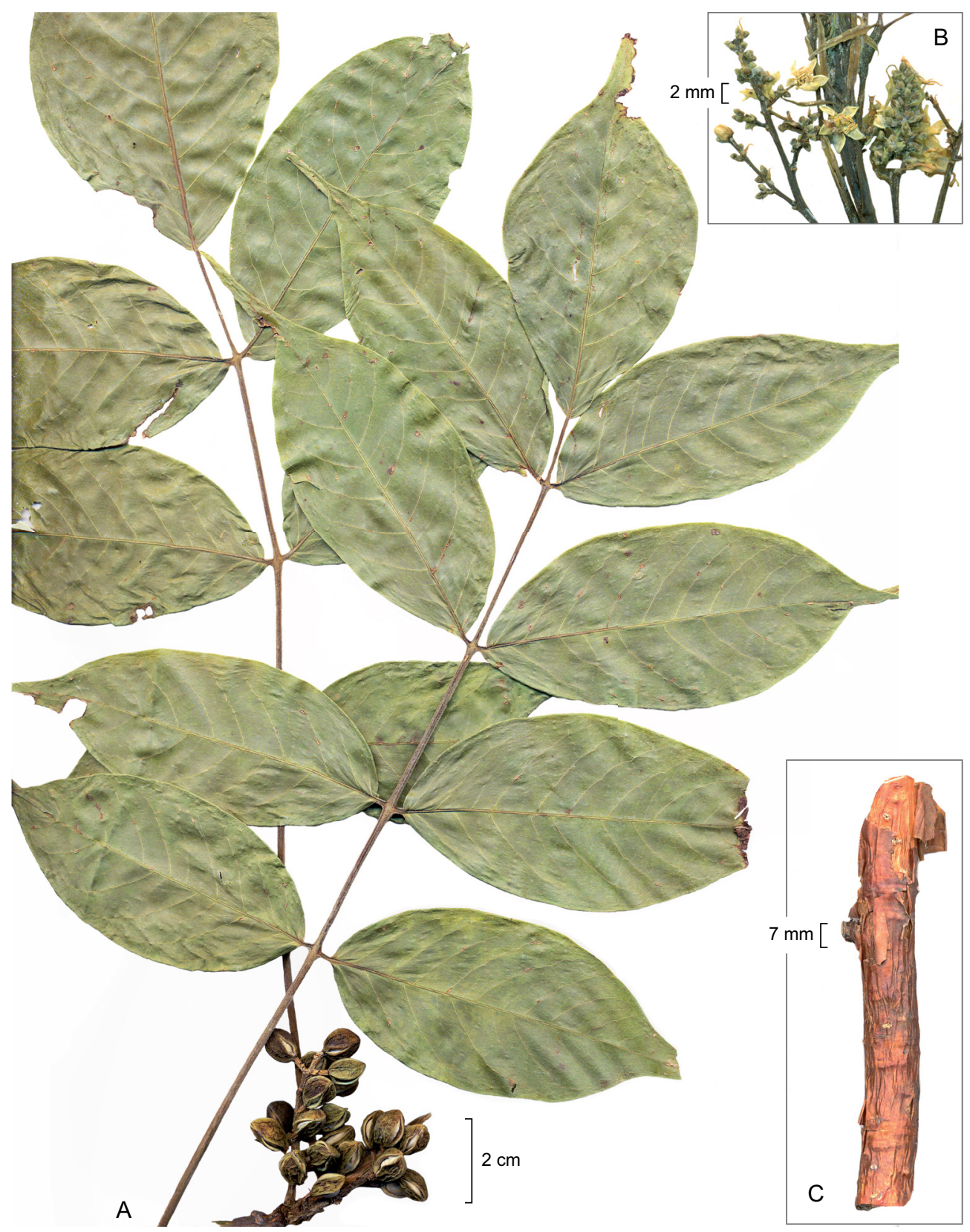

Fig. 8. Bursera roseana. A. rama con frutos; B. detalle de las flores; C. aspecto de la corteza externa. 
triangulares, de poco menos de $1 \mathrm{~mm}$ de largo, pétalos elíptico-oblongos, de 2 a 2.5 $\mathrm{mm}$ de largo, cuculados y encorvados en el ápice, blanquecinos o verdosos, filamentos de $1.5 \mathrm{~mm}$ de largo, anteras oblongas, de $1 \mathrm{~mm}$ de largo, ovario vestigial; flores femeninas similares a las masculinas, anteras de los estaminodios de $0.5 \mathrm{~mm}$ de largo, ovario trilocular, estilo muy breve, estigma trilobado; frutos triquetro-ovoides, de 9 a $12 \mathrm{~mm}$ de largo, glabros, sostenidos por pedicelos notablemente engrosados, huesos de 7 a $9 \mathrm{~mm}$ de largo, totalmente rodeados por el pseudoarilo pálido (Rzedowski et al., 2007).

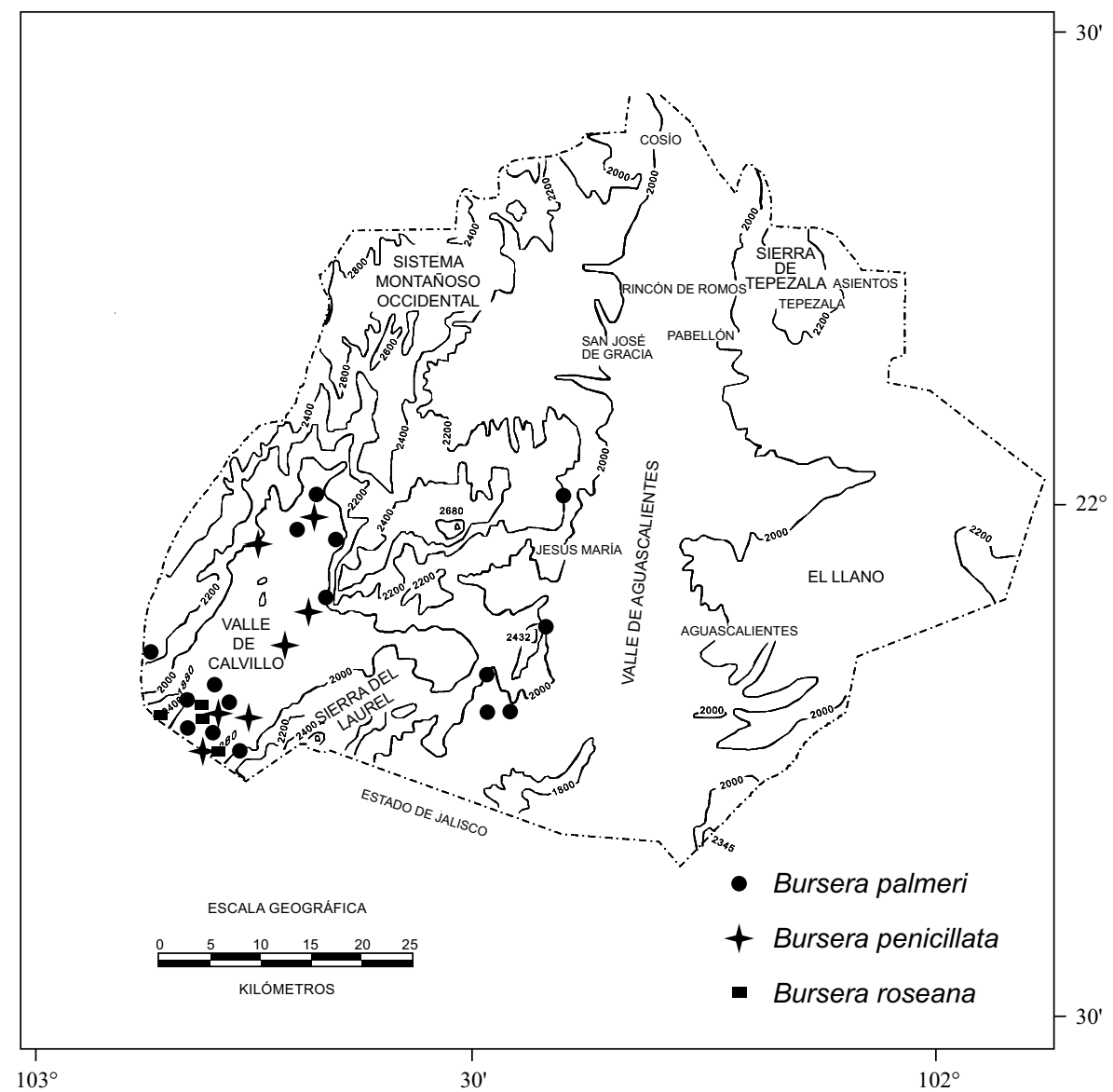

Fig. 9. Distribución de Bursera palmeri, B. penicillata y B. roseana. 
Comentan los pobladores de la región que utilizaban el tronco para la elaboración de bateas, en pocas cercas vivas se emplean los tallos de esta especie.

Especie localizada principalmente a orilla de barrancas y cañadas con selva baja caducifolia. Alt. 1600-1900 m. Florece en mayo y junio, desprovista de follaje de noviembre a mayo.

Se conoce su distribución de Aguascalientes, Colima, Estado de México, Guerrero, Jalisco, Michoacán, Nayarit y Zacatecas.

Ejemplares examinados: municipio Calvillo. $2.7 \mathrm{~km}$ al sur de Presa Los Serna, García G. 4776 (HUAA, IEB); cañada Arroyo Hondo, de la Cerda y García G. 1586 (HUAA); Presa Los Serna, García G. 3429 (HUAA); sureste de la Presa Tres

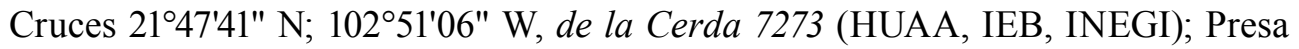

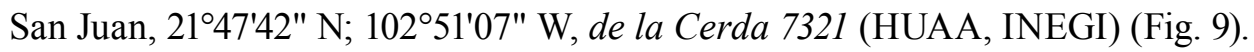

\section{AGRADECIMIENTOS}

La autora agradece a la Universidad Autónoma de Aguascalientes el apoyo brindado a los estudios florísticos del estado de Aguascalientes desde 1980 a la fecha, al Dr. J. Rzedowski por la revisión de la determinación de las especies, a los compañeros del herbario (HUAA) por las colectas realizadas de algunos ejemplares de esta familia, al Biól. Oscar Soto Arellano por el escaneo de los ejemplares de herbario y finalmente a los revisores anónimos que con sus atinadas sugerencias permitieron mejorar la redacción y el contenido del trabajo.

\section{LITERATURA CITADA}

Anónimo. 1981. Síntesis geográfica del estado de Aguascalientes y anexo cartográfico. Secretaría de Programación y Presupuesto. Coordinación Nacional de Estadística, Geografía e Informática. México, D.F.

Bullock, A. A. 1936. Notes on the Mexican species of the genus Bursera. Bull. Misc. Inf. Kew 1936: 346-387.

Cedillo, O. I. y D. Mares E. 1994. Geografía de Aguascalientes. Complemento didáctico. Comisión Estatal de Desarrollo Económico y Comercio Exterior y Gobierno del Estado de Aguascalientes. El Heraldo de Aguascalientes. Aguascalientes, Ags. 158 pp. 
García, E. 1964. Modificaciones al sistema de clasificación climática de Köppen (para adaptarlo a las condiciones de la República Mexicana) Offset Larios. México, D.F. 245 pp.

McVaugh, R. y J. Rzedowski. 1965. Synopsis of the genus Bursera L. in western Mexico, with notes on the material of Bursera collected by Sessé \& Mociño. Kew Bull. 18: 317-382.

Rose, J. N. 1911. Burseraceae. N. Amer. Fl. 25: 241-251.

Rzedowski, J. 1978. Vegetación de México. Editorial Limusa. México, D.F. 432 pp.

Rzedowski, J. y F. Guevara-Féfer. 1992. Burseraceae. Flora del Bajío y de Regiones Adyacentes 3: 1-46.

Rzedowski, J. y G. C. de Rzedowski. 1996. Burseraceae. Flora de Veracruz 94: 1-37.

Rzedowski, J., R. Medina L. y G. C. de Rzedowski. 2004. Las especies de Bursera (Burseraceae) en la cuenca superior del río Papaloapan, México. Acta Bot. Mex. 66: 23-151.

Rzedowski, J., R. Medina-Lemos y G. C. de Rzedowski. 2005. Inventario del conocimiento taxonómico, así como de la diversidad y del endemismo regionales de las especies mexicanas de Bursera (Burseraceae) Acta Bot. Mex. 70: 85-111.

Rzedowski, J., R. Medina L. y G. C. de Rzedowski. 2007. Segunda restauración de Bursera ovalifolia y nombre nuevo para otro componente del complejo de B. simaruba (Burseraceae). Acta Bot. Mex. 81: 45-70.

Standley, P. C. 1923. Burseraceae. Trees and shrubs of Mexico. Contr. U.S. Nat. Herb. 23: 542-552.

Standley, P. y J. Steyermark 1946. Flora of Guatemala. Fieldiana: Botany. Vol. 24. part. V. 434-443 